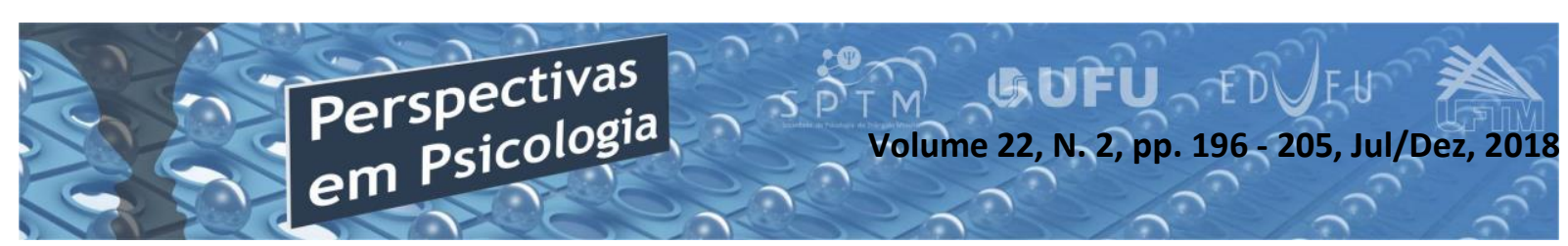

\title{
PERFIL DO HOMEM COM DISFUNÇÃO SEXUAL QUE PROCURA PROFISSIONAL CLÍNICO ESPECIALIZADO EM MEDICINA OU PSICOLOGIA
}

\author{
Juliana Bonetti Simão \\ Pontifícia Universidade Católica de São Paulo - PUC SP, São Paulo - SP \\ Omar Pacheco Simão \\ Universidade Federal de Uberlândia - UFU - Uberlândia - MG
}

\begin{abstract}
Resumo
Este relato de experiência visou elucidar as queixas e problemas de homens que procuram a ajuda de um urologista ou psicólogo especialista em sexualidade. As metodologias utilizadas foram observação direta e análise clínica de pacientes que frequentaram, nos últimos cinco anos, os consultórios de um urologista e de um psicólogo especializado em sexualidade. Os resultados sugerem que a amostra masculina tem disfunção sexual, em sua maioria, por temor de desempenho. Tem também o fanatismo religioso e a homossexualidade latente como possíveis causas. Assim é possível compreender aspectos emocionais semelhantes capazes de agrupá-los em perfis psicológicos para melhor conduzir os casos.
\end{abstract}

Palavras-chave: sexualidade; disfunção sexual masculina; temor de desempenho; fanatismo religioso; homossexualidade latente.

\section{Abstract \\ Profile of men with sexual dysfunction who seek a clinical professional specialized in Medicine or Psychology}

The purpose of this experience report was to elucidate the actual complaints and problems of men who seek help from a urologist or a sex psychologist. The methods we used were direct observation and clinical analysis of patients who visited the offices of a urologist and a sex psychologist in the last five years. Results suggest the male sample has sexual dysfunction, mostly, due to fear of performance. Also has religious fanaticism and latent homosexuality as possible causes. That enabled us to understand similar emotional aspects that group these men into psychological profiles in order to better conduct their treatments.

Keywords: sexuality; male sexual dysfunction; fear of performance; religious fanaticism; latent homosexuality.

\section{Introdução}

O presente relato de experiência pautou-se na observação direta e análise clínica visando à compreensão dos reais conflitos vividos em uma amostra genérica que frequentou os consultórios de um médico urologista e de um psicólogo especialista em sexualidade nos últimos 
cinco anos. A amostra se refere a homens brasileiros com idades entre 18 e 70 anos; todos eram moradores da cidade de São Paulo e redondezas e da cidade de Uberlândia e redondezas; a maioria era de classe média; a maioria era de heterossexuais, sendo que alguns declararam estar em um relacionamento estável e outros, não; e todos possuíam alguma disfunção sexual. Escolheu-se trabalhar com essa população e esse tema em razão da demanda clínica crescente de homens que reconhecem que necessitam de ajuda psicológica para tratar questões relacionadas à sexualidade, além da escassez desse tipo de estudo dentro do espectro da psicologia clínica no Brasil.

Um breve apanhado históricosocial permite-nos entrever mudanças profundas no que tange à sexualidade. Historicamente, as civilizações se edificaram sob a primazia do poder patriarcal (Ramos, Carvalho, \& Leal, 2005). Durante a idade média, a aliança entre poder político e religião ditou, por muito tempo, como a sexualidade seria compreendida. $\mathrm{O}$ ato sexual servia à procriação, e ter filhos representava também mão de obra na lavoura das famílias (Stearns, 2010).

A sexualidade começou a ser um assunto tratado cientificamente a partir do Século XIX, mas apenas em relação a perturbações que se relacionavam às mulheres e não afetavam os homens (Foucault, 1977). Essas perturbações foram amplamente estudadas por Freud (1969) em seus estudos sobre sexualidade e conversões histéricas.

No Século XX, grandes novidades anunciavam novos tempos. O telefone e o automóvel transformaram as relações amorosas. Na década de 1950, com o fim da Segunda Guerra Mundial, com o surgimento do rock and roll e com Elvis Presley rebolando sensualmente na televisão, já se antevia o começo da revolução sexual. Essa revolução teve seu ápice com o advento da pílula anticoncepcional em 1970, pois esta inaugurou, definitivamente, mudanças nas relações de gênero (Lins, 2012).

Atualmente, graças à difusão dos meios modernos de contracepção, observamos uma transformação na intimidade. A sexualidade tornou-se mais livre e fluida, relacionando-se mais com a identidade de cada um do que com uma norma coletiva predeterminada (Del Priore, 2011). Entretanto, em meio a tanta liberação, existe uma parcela de pessoas, e, no caso deste trabalho, uma parcela masculina, que não consegue usufruir dessa liberdade sexual que foi conquistada. A preocupação com o desempenho é tamanha que o sexo se torna um sofrimento. Este artigo comunica sobre a 
vivência afetiva e sexual desse tipo de homem.

\section{Relato da Experiência}

Quando um homem com queixa de disfunção sexual procura um urologista ou um psicólogo especialista em sexualidade, normalmente está em busca de uma solução rápida para o seu problema. Nesse sentido, como é amplamente sabido em Psicologia, o primeiro passo para a melhora é o paciente adquirir consciência da real causa da sua queixa, pois nem sempre está claro para ele o que está por trás das dificuldades enfrentadas. Para tanto, os homens que procuram um profissional especialista em sexualidade geralmente podem ser divididos em dois grandes grupos: a) pacientes de até 45 anos e b) pacientes com mais de 45 anos. No primeiro grupo, a causa da disfunção sexual tem bases quase que exclusivamente psicológicas. Já no segundo grupo, pode-se encontrar uma associação de causas orgânicas e psicológicas em proporção variada. Vale ressaltar que raramente se encontra um paciente com uma base orgânica de disfunção sexual cuja autoconfiança não tenha sido abalada pelas sucessivas falhas. Portanto, a falta de segurança e a intranquilidade durante a relação geram o conhecido temor de desempenho, que está presente em quase todo paciente que procura ajuda médica e psicológica.

Associadas ao temor de desempenho, podemos identificar outras crenças, temores ou fantasias que, uma vez percebidas, podem ajudar o paciente a recuperar sua autoestima. Cabe ao profissional que atende esses pacientes identificar os perfis psicológicos envolvidos, para melhor conduzir os casos. Vejamos a seguir cada um desses perfis.

\subsection{Temor de desempenho gerado pela} cultura machista, que não permite falha

Por qualquer motivo - cansaço, rotina, estresse -, um homem pode vir a falhar em uma relação sexual e, a partir desse único evento, desenvolver uma grande insegurança sexual. Muitas vezes, após um primeiro fracasso, o indivíduo procura ter uma nova relação no dia seguinte, para se testar; ou, o que é pior, busca se testar com uma nova parceira. Contudo, é claro que essa nova relação, em que toda a atenção do homem está focada no pênis, tende ao fracasso, o que só aumenta a sua insegurança. $\mathrm{O}$ caminho de tratamento nesse caso é mostrar ao paciente que ele não é uma máquina, mas um ser humano, e, como ser humano, é dotado de emoções, bem como pode acertar, errar, falhar, ganhar e perder. Tudo isso faz parte da condição humana. O 
tratamento também deve desaconselhar a procura de uma nova parceira somente para o paciente se testar.

\subsection{Temor de desempenho gerado por} uma relação idealizada

O exemplo clássico de temor gerado por uma relação idealizada é o do paciente que chega ao consultório e descreve a parceira como uma verdadeira princesa. Relata que cativou e seduziu a mais linda e perfeita das mulheres durante dias, até que foram ao motel e o paciente não conseguiu ter relação, pois perdeu a ereção no meio do ato sexual ou ejaculou precocemente. Acrescenta que repetiu a tentativa no dia seguinte e amargou um novo fracasso. Chega ao consultório sentindo-se o pior dos homens - um ratinho - tentando ter relações com uma deusa. Cabe ao terapeuta transformar essa deusa em uma mulher e esse ratinho, num homem.

\subsection{Temor de desempenho gerado por} desrespeito a si próprio

"O pênis é anarquista por natureza e só participa de festas para as quais foi convidado e sente-se absolutamente à vontade" (Gikovate, 1989, p. 144). É extremamente comum os homens usarem o sexo como uma droga para anestesiar problemas, suportar frustrações, combater a solidão e lidar com a rotina diária. Esse mal-uso do sexo com finalidade de fugir da terra é feito, muitas vezes, em condições completamente inadequadas.

O exemplo clássico de desrespeito a si próprio é o indivíduo que sai à noite à procura de um encontro e, como este não ocorre, resolve manter relações com uma prostituta ou uma desconhecida pela qual não sente nenhuma atração, cujo cheiro não lhe agrada e que pode até mesmo lhe gerar pensamentos obsessivos sobre a contração de doenças sexualmente transmissíveis. Nesse ambiente de total desrespeito aos sentimentos, o pênis anarquista se rebela e não participa. Essa falha, curiosamente, não é aceita pelo indivíduo, e cabe ao terapeuta, mais uma vez, mostrar-lhe a sua condição humana.

\subsection{Temor de desempenho gerado por mito} referente ao tamanho do pênis

A insatisfação com o tamanho do pênis é uma das queixas mais comuns no consultório do urologista. Os meninos crescem escutando a cultura das ruas, que associa o tamanho do pênis com masculinidade. Alguns homens demonstram enorme complexo de inferioridade com relação ao seu órgão genital, a ponto de não se despirem em vestiários ou na frente da parceira. Isso cria 
uma grande insegurança nesses pacientes, além de fazer com que toda a sua atenção esteja focada em seu pênis. A parceira é percebida apenas como juíza de sua masculinidade, e não como uma companheira, amante, que ali está para uma troca muito mais ampla. Essa genitalização excessiva impede um desempenho sexual satisfatório e, como consequência, o paciente falha muitas vezes, o que cria um ciclo de temor de desempenho. Curiosamente, quase a totalidade desses pacientes tem o pênis dentro dos padrões de normalidade, mas sua referência são atores de filmes pornográficos e informações obtidas pela leitura de revistas masculinas. Além disso, há de se considerar que existe grande variação de tamanho do pênis entre os estados de flacidez e ereção, ou seja, um pênis em estado de ereção pode se tornar bem maior do que aparenta no estado de flacidez.

Com base nesse mito do tamanho do pênis, são cometidas as maiores barbaridades e falcatruas na área médica, submetendo-se homens a cirurgias que prometem o aumento do pênis, mas que geram mudança apenas na sua aparência em estado de flacidez, que é obtida mediante a secção de seu ligamento suspensor.
2.5 Temor de desempenho gerado pelo orgasmo feminino

A televisão e o cinema atual reforçam o mito do chamado orgasmo vaginal e simultâneo. No entanto, muitos estudos mostram que a maioria das mulheres não consegue atingir esse objetivo. Por exemplo, o relatório Hite (1976), uma das mais extensas pesquisas em sexualidade - mesmo com críticas à sua metodologia -, mostrou que cerca de $40 \%$ das mulheres só obtinham orgasmo com a estimulação clitoriana, 30\%, com estimulação clitoriana e com penetração vaginal, $10 \%$, só com penetração vaginal e $20 \%$ eram anorgásmicas primárias. Esses números mostram que, ao contrário do que se vende como idealizado para as mulheres, é com a estimulação clitoriana que a maioria delas atinge o máximo de prazer. Ainda assim, muitos homens se cobram e, ao não conseguirem proporcionar esse orgasmo vaginal concomitante - e até mesmo múltiplo - às suas parceiras, assumem toda a responsabilidade pelo ato, como se esse orgasmo dependesse só deles. Ao não conseguirem sucesso nesse intento, sentem como se a sua masculinidade e o seu pênis fossem inferiores. Cabe ao terapeuta redirecionar o foco da genitália para a troca de carinho no ato sexual, o que pode tornar essa relação muito prazerosa para o casal. 
Temor de Desempenho por Autoestima

\section{Extremamente Baixa}

Existe um grupo de pacientes que acredita que a sua vida não foi destinada ao sucesso. São homens que sempre tiveram muita dificuldade em tudo. Descrevem que, na escola, eram os últimos; namorada, raramente conseguiam; nos esportes, eram um desastre. Pensam que talvez a única situação em que tenham sido os primeiros tenha sido quando o espermatozoide fecundou o óvulo. Esses homens desenvolvem uma autoestima extremamente rebaixada e uma consequente insegurança em relação à sua capacidade sexual. São casos de difícil abordagem terapêutica e que geralmente requerem terapia prolongada, em razão da resistência dos indivíduos.

\subsection{Temor de desempenho devido à castração feminina}

A relação conjugal tem sido objeto de estudos psicológicos devido à sua complexidade. Alguns desses pactos neuróticos são construídos a partir da admiração e da inveja. Mulheres castradoras, segundo a psicanálise, são mulheres que sentem inveja do falo masculino e, por isso, sentem desejo de destruir aquilo que o outro tem e que lhe falta.
Como exemplo, tem-se a situação do homem extremamente fragilizado e dependente que permanece ao lado de uma parceira castradora, que só reforça o insucesso dele e boicota a relação por meio de palavras, atos ou insinuações. Frases como "para que ter relação se você vai brochar?", "seu pênis é de criança", "você é fraco de sexo" e "meu ex-namorado é que era bom amante" são diuturnamente escutadas pelo paciente. Esse homem, às vezes, participa da relação apaticamente.

Mas o problema não envolve apenas a falta de afeição, pois muitas dessas mulheres têm graves dificuldades com a relação sexual, sendo que a transferência de toda a responsabilidade para o homem é uma maneira de não admitirem essas dificuldades para si próprias. Essas mulheres raramente comparecem ao consultório do médico ou do psicólogo e, quando o fazem, são extremamente agressivas.

Curiosamente, esses homens se tornam tão inseguros que são incapazes de procurar outro relacionamento. $\mathrm{O}$ tratamento desses indivíduos é extremamente melindroso, pois o paciente tem que perceber esse boicote sem que o terapeuta lhe diga isso claramente. Deve-se tentar mobilizar a parceira para tratamento. Nos casos em que não existe mais nenhuma afeição ou amor, é comum a separação do casal. Nos casos de extrema 
resistência da mulher em se mobilizar e de extrema dependência do indivíduo, é comum a perda do cliente pelo terapeuta.

\subsection{Religioso fanático}

Nos dias de hoje, com as religiões proliferando à solta, têm surgido algumas religiões extremamente rígidas. Consequentemente, tem aumentado muito o número de homens que são moldados sob essas intensas restrições. Tudo é pecado e tudo é proibido. A relação sexual desses pacientes é orientada apenas para reprodução, e todas as outras formas de sexo são revestidas de intensa culpa. Muitos desses pacientes são casados com mulheres criadas no mesmo ambiente restritivo, e a relação desse casal é extremamente empobrecida, pois se sentem pecadores ao perceberem qualquer excitação. Aqui também o tratamento é melindroso, porque qualquer movimento do terapeuta vai de encontro à religião do paciente. Técnicas de relaxamento sexual, masturbação, sexo oral, fantasias e posições são proibidas pela religião.

\subsection{Homossexualidade latente}

Alguns pacientes procuram ajuda relatando dificuldade sexual com as mulheres, mas, no decorrer da entrevista, o que se pode notar é a falta de atração pelo sexo oposto, com nítida tendência homossexual. Contudo, apesar das fantasias, desejos e atração homossexuais, a questão ainda não está completamente clara e resolvida para esses indivíduos.

Por motivos culturais, por comportamento semelhante ao grupo de amigos ou para manter as aparências, esse homem homossexual tenta manter relações com mulheres, ainda que não sinta nenhuma atração ou desejo por elas. Claro que o resultado é a perda ou falta de ereção. O terapeuta tem a árdua tarefa de ajudar esse paciente a encontrar seu caminho, sem induzi-lo.

\section{Discussão e Conclusão do Relato de Experiência}

$\mathrm{Na}$ amostra estudada, identificaram-se homens que trazem, junto à sua vivência sexual, mitos e crenças herdados de uma cultura patriarcal que corrobora uma falsa imagem masculina. Trata-se de uma amostra que espera corresponder a um ideal de masculinidade inatingível, que não lida bem com o fracasso e que, em consequência, desenvolve a disfunção sexual como sintoma. Paradoxalmente, o homem que não se permite falhar no sexo provavelmente vai falhar, enquanto que aquele que admite para si mesmo que a falha é algo possível dificilmente irá 
vivenciá-la. A solução está em reconhecer a situação como natural e saber lidar com ela como tal (G. Lopes, comunicação pessoal, 17 de fevereiro de 2017).

Para Carelli (2013), foi a partir da Revolução Sexual Feminina que emergiram estereótipos masculinos que enaltecem a prática sexual performática e que impõem ao homem ter que estar sempre disposto para o sexo, independentemente do momento, da parceira e dos próprios sentimentos. Neste trabalho, esses estereótipos e as suas consequências na vivência sexual masculina foram observados especificamente no perfil masculino que vivencia o temor de desempenho gerado pelo orgasmo feminino, no perfil masculino que desrespeita a si próprio, no perfil masculino que vivencia o temor de desempenho devido a uma relação idealizada e no perfil masculino que não se permite falhar devido à cultura machista. Conclui-se que o homem enquadrado em algum desses perfis se sente responsável por dar prazer à parceira, proporcionandolhe o orgasmo; ele não se permite recusar uma investida sexual e, muito menos, falhar, pois tudo isso reflete na sua autoavaliação de desempenho sexual. De acordo com Simão (2017), o homem que se sente responsável pelo prazer e orgasmo femininos é aquele que desconhece o próprio gozo, a própria sensualidade e sexualidade, uma vez que é através do gozo delas que valida a própria potência sexual.

Por outro lado, a ligação entre religião e sexualidade não é recente (Stearns, 2010). O perfil masculino com disfunção sexual devido ao fanatismo religioso é frequente na clínica. De acordo com França (2004), a formação religiosa extremamente rígida é um dos fatores predisponentes para a disfunção erétil de origem psicogênica, por exemplo. A abordagem com esse tipo de cliente deve ser cautelosa e pautada no respeito à sua crença.

Quanto ao perfil do paciente que se sente inseguro em relação ao tamanho do pênis, é possível afirmar que esse é um dos mitos construídos socialmente que mais preocupam uma grande parcela da população masculina. Isso ocorre porque o falo foi associado historicamente a virilidade, potência e masculinidade (Reis, Glina, \& Abdo, 2014). Essa crença, porém, em nada procede. Esse tipo de paciente busca ajuda primeiramente médica, e, num segundo momento, pode vir a buscar algum tipo de apoio psicológico.

Por fim, quanto ao perfil do paciente que possui disfunção sexual devido à homossexualidade latente, Pedrosa (2006) pontua que a prática homossexual é, ainda hoje, condenada, pois é vista como antinatural, embora não 
seja. Essa visão contribui para o isolamento social do homem gay e para o aumento da violência física contra a pessoa homossexual. Para se protegerem do isolamento, muitos gays partem para uma relação heterossexual, casando-se e constituindo família. Nos primeiros anos de relacionamento heterossexual, esses homens conseguem ter uma vida sexual pouco regular com a esposa. Depois, a tendência é uma diminuição dos encontros sexuais. Com o passar do tempo, o impulso sexual diminui, minimizando a possibilidade de ocorrer uma ereção com a mulher. A tendência é essa possibilidade se extinguir. Ele passa a ter ereção exclusivamente com o objeto de seu desejo, isso é, outro homem. A parceira acaba se resignando, mesmo sem entender direito o que está ocorrendo; ela permanece casada pelos filhos e pelos bens materiais acumulados.

Conclui-se, com esta breve comunicação, que muito se fala sobre sexo na atualidade, mas poucos são aqueles que se apropriam da experiência sexual de forma total. Isso quer dizer que a sexualidade, hoje exposta e exibida ao extremo, continua a ser um ponto nevrálgico na vida de muita gente. $\mathrm{O}$ principal órgão sexual humano é o cérebro. O sexo começa na cabeça. As crenças sexuais precisam ser questionadas e derrubadas para que então se tenha uma experiência verdadeiramente prazerosa na vivência da sexualidade em toda a sua simplicidade.

\section{Referências}

Carelli, A. R. (2013). A sexualidade humana do passado ao presente. In A. Diehl; D. Leite Vieira (Eds.), Sexualidade: do prazer ao sofrer (pp. 1-38). São Paulo: Editora Roca. Del Priore, M. (2011) Histórias íntimas: sexualidade e erotismo na história do Brasil. São Paulo: Planeta.

Foucault, M. (1977). A vontade de saber. In M. T. C. Albuquerque \& J. A. G. Albuquerque (Trans.), História da sexualidade (Vol. 1). Rio de Janeiro: Graal.

França, C. P. (2004). Ejaculação Precoce e Disfunção Erétil: uma abordagem psicanalítica. 2nd ed. São Paulo: Casa do Psicólogo.

Freud, S. (1969). Um Caso de Histeria, Três Ensaios sobre Sexualidade e outros trabalhos (1901-1905). In J. O. A. Abreu (Trans.), Edição Standard Brasileira de Obras Psicológicas Completas de Sigmund Freud (Vol. 7). Rio de Janeiro: Imago. Gikovate, F. (1989). Homem: o sexo frágil? São Paulo: MG editores. 
Hite, S. (1976). The Hite report: a nationwide study off female sexuality. New York: Dell Publishing.

Lins, R. N. (2012). O livro do amor: do iluminismo à atualidade. Rio de Janeiro: Best Seller.

Pedrosa, J. B. (2006). Segundo desejo. São Paulo: Editora Iglu.

Ramos, V.; Carvalho, C. C.; Leal, I. P. (2005). Atitudes e comportamentos sexuais de mulheres universitárias: a hipótese do duplo padrão sexual. Análise psicológica, 23(2), 173-185. doi: https://doi.org/10.14417/ap.80.

Reis, M. M. F.; Glina, S., Abdo, C. H. N. (2014). Percepção sobre o tamanho do pênis em homens brasileiros supostamente saudáveis de 40 a 60 anos: um estudo piloto transversal. São Paulo Med J, 133(2), 84-90. doi: http://dx.doi.org/10.1590/15163180.2013.7710008.

Simão, J. B. (2017). A gente se vê por aí... motivações, atitudes e comportamentos de homens e mulheres heterossexuais adultos sobre o sexo sem compromisso (Dissertação de Mestrado não publicada). Pontifícia Universidade Católica de São Paulo, São Paulo. Stearns, P. N. (2010). História da sexualidade. São Paulo: Contexto.

\section{Os Autores:}

Juliana Bonetti Simão é graduada em psicologia pela Uni FMU de São Paulo. Mestre em psicologia clínica junguiana pela Pontifícia Universidade Católica de São Paulo. Especialista em Psicoterapia com Foco na Sexualidade pelo Instituto Paulista de Sexualidade. Pós-graduada em psicanálise para a formação de psicoterapeutas pela Universidade Federal de São Paulo. E-mail: julianabonettisimao@ gmail.com

Omar Pacheco Simão é médico graduado pela Universidade Federal de Uberlândia, com título de especialista pela Sociedade Brasileira de Urologia, Mestre e Doutor em medicina pela Universidade Federal de São Paulo, responsável chefe pelo serviço e pela residência médica em urologia na UFU e professor titular de urologia da Universidade Federal de Uberlândia. E-mail: omarpachecosimao@ gmail.com

Recebido em: 08/12/2018.

Aprovado em: 26/12/2018 